\title{
Shear Behaviors of the Intersurface between Rice Straw Rope and Dredger Fill Silt: Experimental and Mechanism Studies
}

\author{
Guizhong Xu $\mathbb{D}^{1},{ }^{1}$ Ji Chen, ${ }^{2}$ Shenjie Shi, ${ }^{2}$ Angran Tian, ${ }^{2}$ and Qiang Tang $\mathbb{D}^{2,3}$ \\ ${ }^{1}$ Geotechnical Research Institute, Yancheng Institute of Technology, No. 9, Xiwang Road, Yancheng 224051, China \\ ${ }^{2}$ School of Rail Transportation, Soochow University, Xiangcheng District, Suzhou 215131, China \\ ${ }^{3}$ Graduate School of Global Environmental Studies, Kyoto University, Sakyo-ku, Kyoto 606-8501, Japan
}

Correspondence should be addressed to Qiang Tang; tangqiang@suda.edu.cn

Received 11 December 2019; Accepted 24 January 2020; Published 13 February 2020

Guest Editor: Junhui Zhang

Copyright ( $\odot 2020$ Guizhong Xu et al. This is an open access article distributed under the Creative Commons Attribution License, which permits unrestricted use, distribution, and reproduction in any medium, provided the original work is properly cited.

The further development of land reclamation, port waterway, and wharf construction brings about proper treatments of dredger fill silt, while huge amounts of rice straw set aside in China argument rational disposal every year. Therefore, rice straw is bundled up as ropes, which represent as drainage body and reinforcement, to make eco-friendly treatment for dredger fill silt. This paper investigates the mechanical properties and validity of rice straw rope as certain treating material of dredger fill silt through a series of pull-out test, mass loss test, and tension test on specimens with different water contents and dry densities. The results reveal that peak value of interfacial shear strength rises with the increase of normal stress at the same immersion time, and in particular, it rises by up to $250.0 \%$ when the normal stress is $40 \mathrm{kPa}$. The tensile force of rice straw rope increases slowly with the rise of tensile displacement, and the failure mode changes from brittle to ductile with the rise of immersion time, which witnesses first rapid back slow degradation trend. The proper interfacial shear strength, tensile force, and reasonable degradation rate of rice straw rope make it ideal in drainage and consolidation of dredger fill silt.

\section{Introduction}

The further development of land reclamation, port waterway, and wharf construction brings more than billions of cubic meters of dredger fill silt every year. The dredger fill silt has the characteristics of large void ratio, high water content, low strength, and high compressibility. The self-consolidation time of silt is long, which leads to large consolidation settlement and obvious deformation after loading [1-4]. The conventional methods of soft soil treatment include displacement method, drainage method, dynamic consolidation method, or combined consolidation method [5-9]. Alternative methods, which depend on dry jet mixing piles or cement fly-ash gravel (CFG) piles for driveway drainage, are relatively expensive. Dynamic compaction and combined reinforcement are the most widely used large-scale soil treatment methods except for the high groundwater level in the construction site [10-13]. Vacuum preloading and surcharge preloading are two common methods used to reduce the water content. Prefabricated strip and the layered horizontal plastic drainage strip were used to accelerate the consolidation of dredger fill $[14,15]$. The self-weight consolidation and load consolidation of high water content dredged soil are verified by the indoor test of high water content dredged soil [16-18]. Nowadays, plastic board is generally used as vertical drainage bodies, which can not only drain water but also improve the bearing capacity of dredger fill foundation [19-21].

With the development of agricultural science and technology in China, crop straw resources are becoming more and more excessive. It is estimated that around 700 million tons of crop straw are generated in China per year and rice straw accounts for one-third of the total. As natural fibers are extremely cheap, locally available, and ecofriendly, straw has been successfully utilized in a variety of beneficial applications over the past few decades, especially in civil engineering applications [22-25]. Coir fiber, sisal fiber, jute fiber, wheat fiber, and other natural fibers are 
widely researched and applied [26-28]. The main role of reinforcement is to enhance the integrity of the soil and maintain a certain degree of continuity. The reinforced mechanism not only restricts the lateral displacement of soil that increases the stiffness of soil but also improves the strength and stability of reinforced soil. As an effective technology to improve soil mechanism, reinforced soil has been widely used in road engineering construction and other fields. In the analysis of soil internal stability and interface interaction, pull-out test seems to be the most widely used method due to its simplicity and usability [29]. In order to investigate the tensile strength of reinforced soil, tension tests are necessary. Rice straw is used to make simple drainage bodies in the drainage and consolidation of dredge fill silt. When rice straw is selected as vertical drainage body, the straw also acts as reinforced material.

In this study, rice straw was bound up as ropes. Mass loss test, tension test, and pull-out test were conducted to analyze the interfacial mass loss, tensile properties, and interface characteristics of rice straw rope. The objective of this paper is to study the properties and mechanics of rice straw rope through tests and provide a theoretical basis for treating dredger fill silt with rice straw rope.

\section{Materials and Methods}

2.1. Materials. The rice straw rope for tests in this paper is obtained from Suqian, Jiangsu Province, China. These straw ropes are $1 \mathrm{~cm}$ in diameter, as shown in Figure 1. The high yield of rice in Jiangsu has brought a large amount of rice straw to be treated every year. The rational utilization of rice straw will contribute to the sustainable development of this region. In this paper, dredger fill silt with high water content was taken from the bottom of Huai River in Bengbu City, Anhui Province. The dredger fill silt is cohesive soil, with WL (liquid limit) of 53.81\%, WP (plastic limit) of $27.86 \%$, and IP (plasticity) of $25.95 \%$.

2.2. Test Equipment. A self-made pull-out test system was fixed to figure out the interfacial friction parameters between rice straw and silt, as shown in Figure 2. This equipment controls the pull-out test speed and tension force by stepping motor and the whole process of the test is controlled by computer. The sample can be drawn horizontally at a constant pull-out test speed and tension force, and the parameters such as pull-out test force and displacement can be measured. The main technical indexes of this equipment are shown in Table 1. A small-range tension test machine was also prepared to study the tensile properties of rice straw rope under different immersion time.

\subsection{Methods}

2.3.1. Pull-Out Test. During immersion, the two ends of the samples were tightened with plastic straps to avoid loosening. A time schedule of immersion was formulated to avoid the samples not be carried out immediately. Five groups of rice straw rope were immersed, three in each

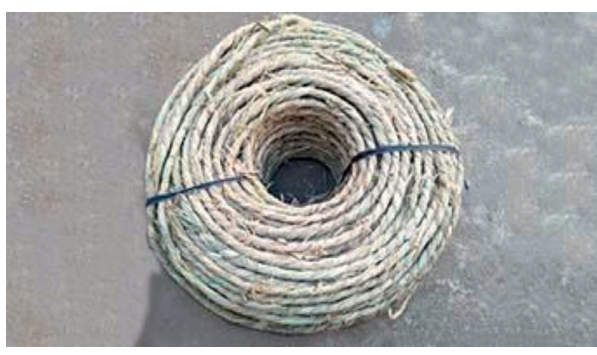

Figure 1: Straw rope.

group. After 5 days' immersion, the first group of samples was put out, while the second after 10 days, the third after 20 days, the fourth after 40 days, and the fifth after 60 days. The pull-out test equipment was dripped by dry glue for reinforcement. Put the wet sample into the pull-out test box, fill the silt layer by layer into the pull-out test box, and compact properly until the upper half of the box is filled. Then cover the plate and fix the normal stress-exerting device. A dial indicator was set on the cover plate to monitor the settlement of the silt surface under different normal stress. These tests aim to evaluate the friction strength at the interface and friction ratio of dredger fill silt with the rice straw rope.

Friction strength and friction ratio are calculated according to the following formulas:

$$
\tau_{P}=\frac{F}{\pi L D},
$$

where $\tau_{P}$ is pull-out test friction strength, $F$ is maximum pull-out test force, $L$ is the embedded length of the sample, and $D$ is diameter of sample.

$$
f=\frac{\tau_{P}}{P},
$$

where $f$ is pull-out test friction ratio, $\tau_{P}$ is pull-out test friction strength corresponding to $P$, and $P$ is normal pressure.

2.3.2. Mass Loss Test. Five groups of rice straw rope were immersed, three in each group, in five white plastic containers with water. The containers were sealed with freshkeeping film to prevent water evaporation. The first group of samples was put out after 5 days' immersion and dried on 50 Celsius until constant weight, while the second after 10 days, the third after 20 days, the fourth after 40 days, and the fifth after 60 days. The oven used in this test is DHG-101-0 electrothermal constant temperature drying oven. When the sample was cooled to room temperature, the mass of the sample after drying was recorded by an electronic scale with an accuracy of $0.01 \mathrm{~g}$. The purpose of this test is to study the degradation properties of rice straw rope.

Rice straw rope began to degrade after immersion in water for a certain time, and rice straw fibers were gradually decomposed. The mass of rice straw rope declined gradually. Therefore, the mass of rice straw rope was taken as the control factor and the degradation degree was evaluated by mass loss rate as follows: 


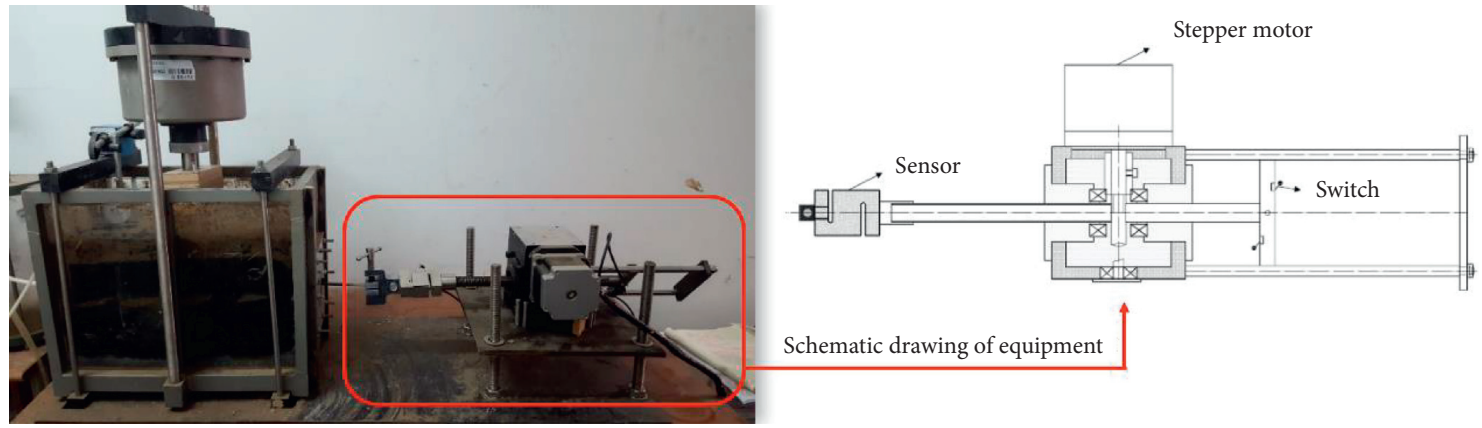

Figure 2: Pull-out test system.

TABLE 1: Main technical indexes of pull-out test equipment.

\begin{tabular}{|c|c|c|c|c|}
\hline $\begin{array}{l}\text { Range of pull-out test rate } \\
(\mathrm{mm} / \mathrm{min})\end{array}$ & $\begin{array}{c}\text { Range of displacement } \\
\text { measurement }(\mathrm{mm})\end{array}$ & $\begin{array}{l}\text { Resolution ratio } \\
(\mathrm{mm})\end{array}$ & $\begin{array}{l}\text { Range of pull-out test force } \\
\text { measurement }(\mathrm{N})\end{array}$ & $\begin{array}{c}\text { Accuracy } \\
(\%)\end{array}$ \\
\hline $0.03-3.0$ & $0-170$ & 0.01 & $0-2000$ & 1 \\
\hline
\end{tabular}

$$
R=\frac{m-m_{0}}{m} \times 100 \%,
$$

where $R$ is rate of mass loss, $m$ is original mass of sample, and $m_{0}$ is sample mass after drying.

2.3.3. Tension Test. Five groups of rice straw rope were immersed, three in each group, in five white plastic containers with water. The containers were sealed with freshkeeping film to prevent water evaporation. The first group of samples was put out after 5 days' immersion, while the second after 10 days, the third after 20 days, the fourth after 40 days, and the fifth after 60 days. Dry glue was dripped at clamping end to make the failure point in the middle of $100 \mathrm{~mm}$ during tension test. Install the testing machine and set the tension rate to $5 \mathrm{~mm} / \mathrm{min}$. Start the machine and begin the tension test. The purpose of this test is to study the tensile properties and deterioration properties of rice straw rope under different immersion time. Elongation is one of the important bases to judge whether the drainage body is qualified or not. According to the relevant provisions of JTS 206-1-2009, the elongation is calculated according to the following formula:

$$
\varepsilon=\frac{\Delta L}{L_{0}} \times 100 \%,
$$

where $\varepsilon$ is rate of elongation, $\Delta L$ is elongation of sample measured length at peak tensile force, and $L_{0}$ is measured length of sample.

\section{Results and Discussions}

3.1. Pull-Out Test Results. The pull-out test results are presented in Figure 3 for samples at different immersion time of $5,10,20,40$, and 60 days and various vertical pressures of $20,40,60$, and $80 \mathrm{kPa}$. It can be noted that the interfacial shear strength increases almost linearly with the rise of horizontal displacement. When reaching a certain point, it changes to a nonlinear rise and reaches the ultimate interfacial shear strength shortly afterwards. When the interfacial shear strength reaches its peak value, it will remain at the peak for a period of time and then decrease slowly. In other words, it takes some time from the peak shear strength to the failure. Interfacial shear strength is the key factor to control the toughness and mechanical properties of materials [30-32]. By comparing Figures 3(a)-(d), it is found that the interface between rice straw rope and silt needs longer time to be completely destroyed under high normal stress. After the failure of the interface, the shear strength decreases slowly and finally converges to a lower limiting value. When the normal stress is $60 \mathrm{kPa}$ and $80 \mathrm{kPa}$, the shear strength decreases further with the increase of horizontal displacement and enters a state similar to creep deformation. In the pull-out test, the pull-out performance of reinforcement is affected by many factors. Lopes show that the increase of limiting stress, dry density, or displacement rate will increase the shear strength of soil [33-35].

The peak values of interfacial shear strength between rice straw rope and dredger fill silt are shown in Table 2 . When the immersion time increased from 5 days to 60 days and under the normal stress of $20,40,60$, and $80 \mathrm{kPa}$, the peak values of interfacial shear strength decreased by $23.2 \%$, $34.86 \%, 33.37 \%$, and $22.83 \%$, respectively. The result indicates that the immersion time has a great influence on the shear strength of the interface between pull-out test specimens of rice straw rope and dredger fill silt. An interfacial shear strength curve under different immersion time is shown in Figure 4, which is obtained by linear fitting of the relationship between the peak value of interfacial shear strength and normal stress. The essence of this process is actual M-C criterion, and the formula is as follows:

$$
\tau=\sigma \tan \varphi+c
$$

where $\tau$ is interface shear strength, $\sigma$ is normal stress, $\varphi$ is interfacial friction angle, and $c$ is interfacial cohesion. 


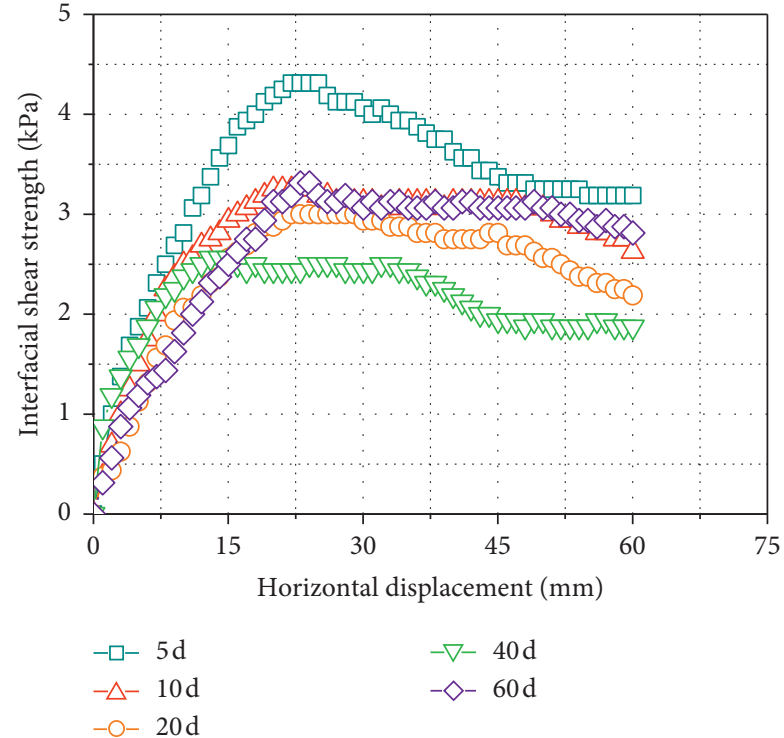

(a)

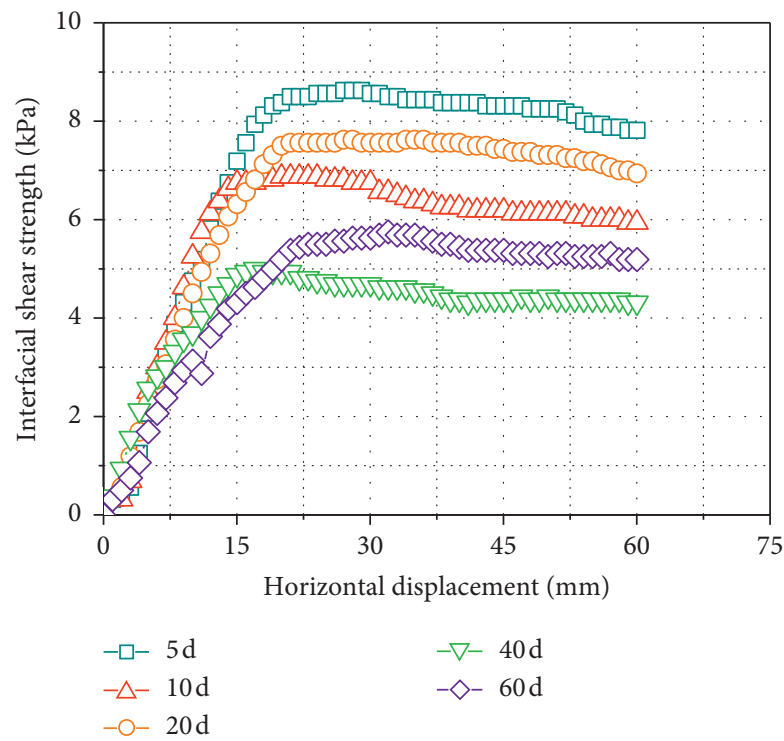

(c)

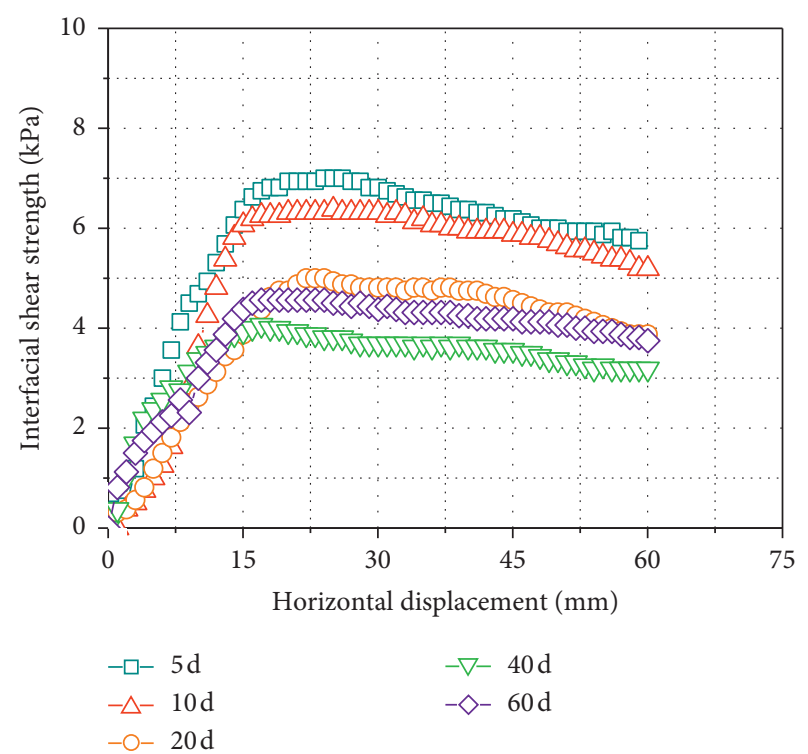

(b)

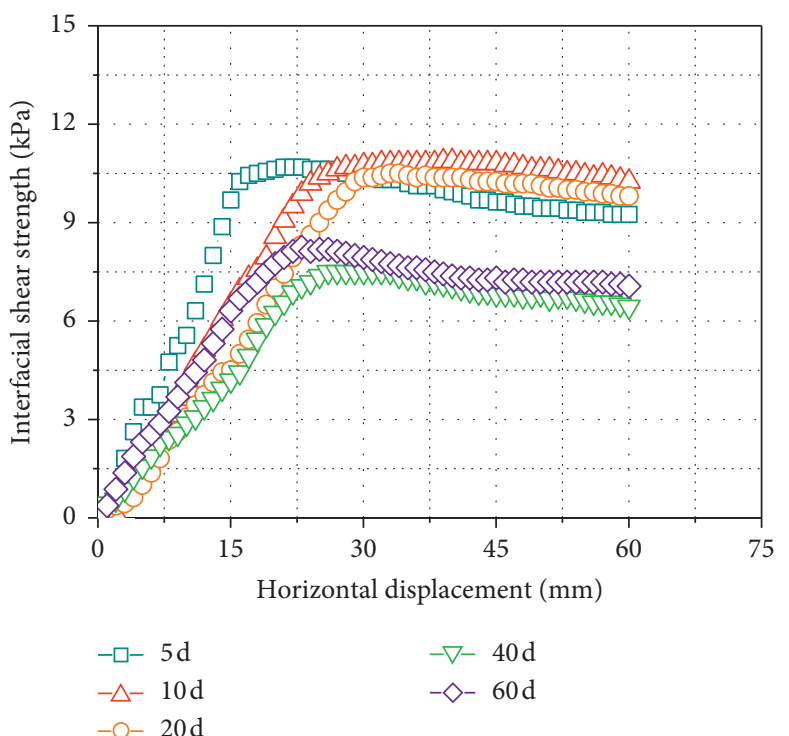

(d)

FIgURE 3: Curve of shear strength of interface with horizontal displacement under different immersion time. (a) $20 \mathrm{kPa}$, (b) $40 \mathrm{kPa}$, (c) $60 \mathrm{kPa}$, and (d) $80 \mathrm{kPa}$.

TABle 2: Peak values of interfacial shear strength.

\begin{tabular}{lcccc}
\hline \multirow{2}{*}{ Immersion time (d) } & \multicolumn{4}{c}{ Normal stress $(\mathrm{kPa})$} \\
\hline 5 & 20 & 40 & 60 & 80 \\
10 & 4.31 & 7 & 8.63 & 10.69 \\
20 & 3.25 & 6.38 & 6.88 & 10.88 \\
40 & 3 & 5 & 7.63 & 10.5 \\
60 & 2.56 & 4.06 & 5 & 7.5 \\
\hline
\end{tabular}

The interfacial shear strength indexes under different immersion time are shown in Table 3. There is a certain interfacial cohesion at the interface of rice straw rope and dredger fill silt [36-40]. With the increase of immersion time, the interfacial cohesion decreases after 20 days' immersion and then increases, while the interfacial friction angle increases first and then decreases. This is because the degradation degree of specimens has a great influence on the peak value of interfacial shear strength when the normal stress is low and 20 days before immersion. With the increase of the normal stress, the influence decreases gradually. It results in the decrease of ultimate shear strength's difference value with the increase of immersion time under the same normal stress and different immersion time. Fiber improves the mechanical properties of soil through the interfacial friction between fiber and soil particles and the spatial confinement effect of fiber [41-44]. 


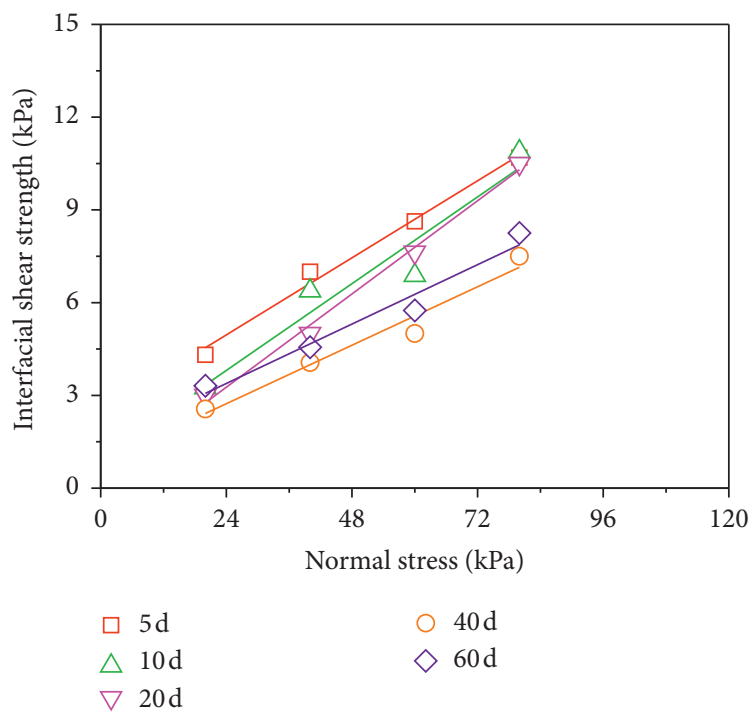

Figure 4: Interfacial shear strength curve under different immersion time.

TABLE 3: Interface shear strength indexes under different immersion times.

\begin{tabular}{lcc}
\hline Immersion time $(\mathrm{d})$ & Interfacial cohesion c $(\mathrm{kPa})$ & Interfacial friction angle $\varphi /\left(^{\circ}\right)$ \\
\hline 5 & 2.465 & 5.932 \\
10 & 1.00 & 6.673 \\
20 & 0.25 & 7.165 \\
40 & 0.84 & 4.506 \\
60 & 1.465 & 4.58 \\
\hline
\end{tabular}

The samples are at different normal stress of 20,40,60, and $80 \mathrm{kPa}$ and various immersion time of $5,10,20,40$, and 60 days, as shown in Figure 5. It is noted that the shear strength of the interface between rice straw rope and dredger fill silt increases with the rise of horizontal displacement and decreases slowly after reaching the peak value. The peak value of interfacial shear strength increases with the rise of normal stress after the same immersion time. When the normal stress increases from $20 \mathrm{kPa}$ to $80 \mathrm{kPa}$, the peak shear strength increases by $148.03 \%$, $234.77 \%, 250.0 \%, 192.97 \%$, and $149.24 \%$, respectively, under five immersion times. It means that the increase of normal stress can greatly improve the shear strength of the interface between rice straw rope and silt. With the increase of normal stress, the frictional resistance between silt particles increases gradually. It limits the displacement of silt particles which embeds the silt particles in the thread of the straw rope and straw gap. As a result, it improves the "biting" effect between the straw rope and the silt and increases the shear strength of the interface $[45,46]$. The interfacial friction coefficient of rice straw rope and silt under different normal stresses is shown in Table 4. The interfacial friction coefficient decreases with the increase of normal stress at the same immersion time. Under the same normal stress, the interfacial friction coefficient decreases first and then increases with the rise of immersion time.
In the pull-out test, the surface of the sample is covered by silt when the normal stress reached $80 \mathrm{kPa}$, as shown in Figure 6. This is because the displacement of silt particles is restrained under the action of high normal stress. Silt particles embedded gradually in the sample, forming a certain thickness of "silt skin" on the surface of the sample, which results in friction between the sample and silt.

3.2. Mass Loss Test Results. The rate of mass loss can show the degradation of rice straw rope directly. The curve of the average mass loss rate of rice straw with immersion time is shown in Figure 7. In this figure, the average mass loss rate of rice straw in water increases with immersion time. During the period from 0 to 20 days of immersion, the average mass loss rate increased linearly. The average mass loss increased by $44.25 \%$ in 20 days. During 20 to 40 days of immersion, the average mass loss increased by only $1.13 \%$. During the period from 40 days to 60 days of immersion, the average mass loss increased gradually, but the increase was not as high as that in the previous 15 days. The average mass loss of rice straw increased by $9.34 \%$ in the last 20 days.

The degradation of rice straw in water has gone through two stages, as shown in Figure 7. The first stage is rapid degradation (immersion for 0 to 20 days), which accounts for $80.87 \%$ of the total. The second stage is slow degradation (immersion for 20 to 60 days). Compared with the first stage, 

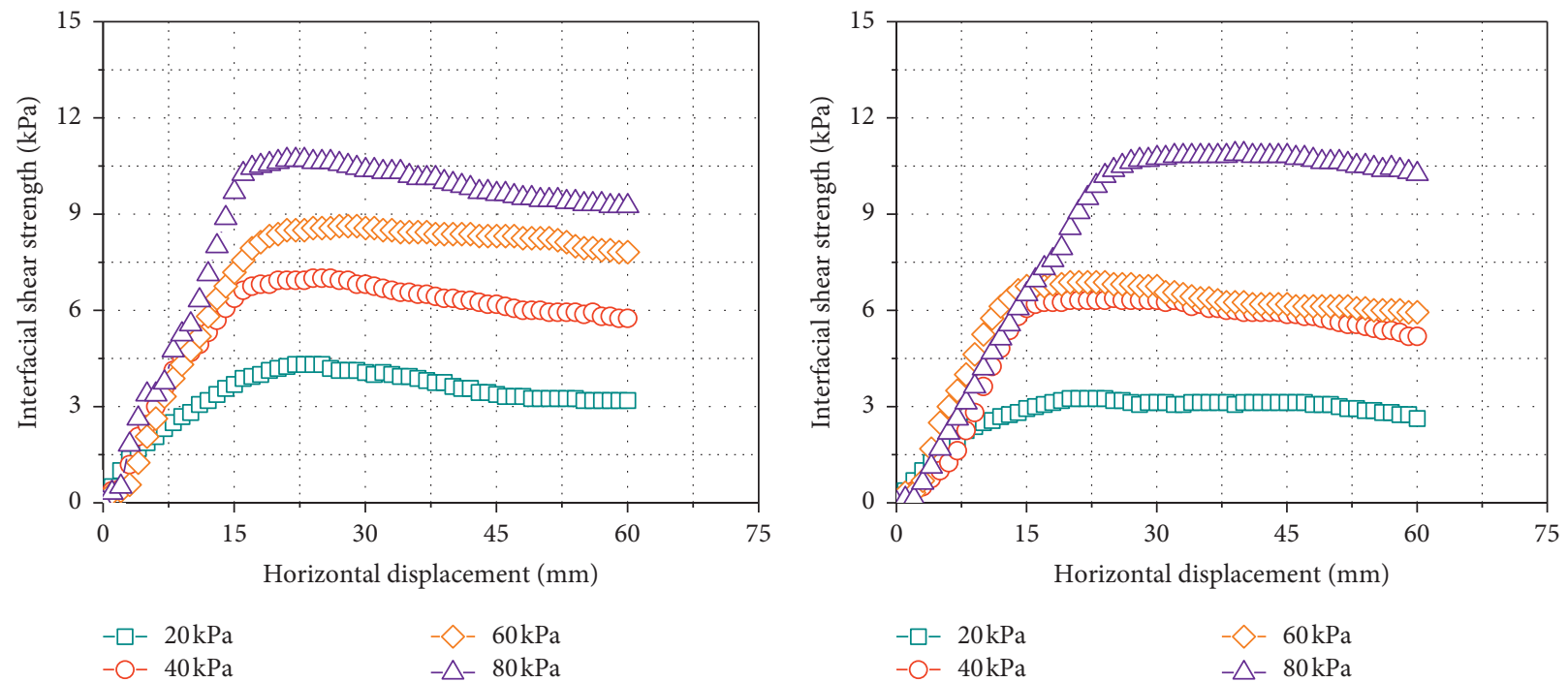

(a)

(b)
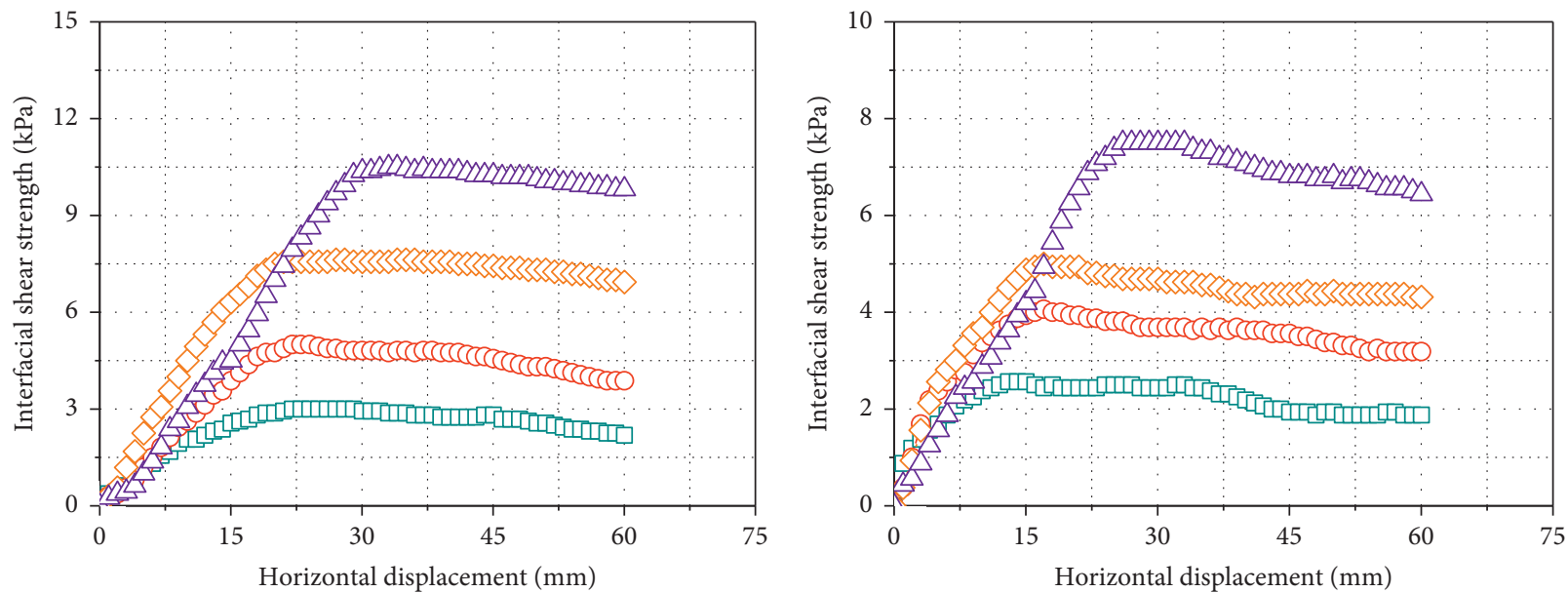
$-\square-20 \mathrm{kPa}$
$-\diamond-60 \mathrm{kPa}$
-O- $40 \mathrm{kPa}$
$-\triangle-80 \mathrm{kPa}$

$-\square-20 \mathrm{kPa}$

$\checkmark-60 \mathrm{kPa}$

(c)

(d)

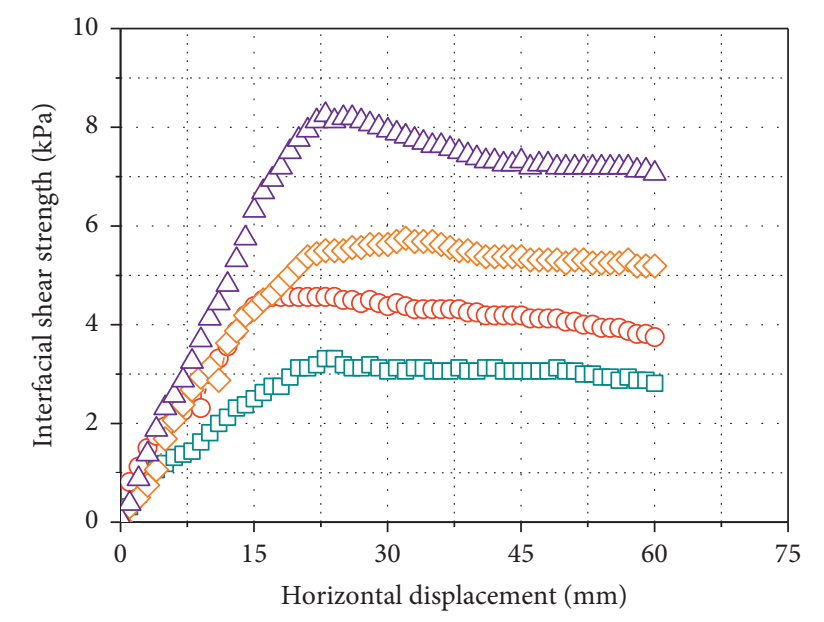

$$
\begin{array}{ll}
-\square-20 \mathrm{kpa} & -\checkmark-60 \mathrm{kpa} \\
-\bigcirc-40 \mathrm{kpa} & -\triangle-80 \mathrm{kpa}
\end{array}
$$

(e)

Figure 5: Curve of interface shear strength with horizontal displacement under different normal stress. (a) $5 \mathrm{~d}$, (b) $10 \mathrm{~d}$, (c) $20 \mathrm{~d}$, (d) $40 \mathrm{~d}$, and (e) $60 \mathrm{~d}$. 
TABLE 4: Interfacial friction coefficient under different normal stresses.

\begin{tabular}{lccccc}
\hline \multirow{2}{*}{ Normal stress $(\mathrm{kPa})$} & \multicolumn{4}{c}{ Friction coefficient c $(\mathrm{kPa})$} \\
& 5 & 10 & 20 & 0.15 & 0.13 \\
\hline 20 & 0.22 & 0.16 & 0.13 & 0.1 & 0.17 \\
40 & 0.18 & 0.16 & 0.13 & 0.11 \\
60 & 0.14 & 0.13 & 0.13 & 0.1 \\
80 & 0.13 & 0.13 & 0.09 & 0.1 \\
\hline
\end{tabular}

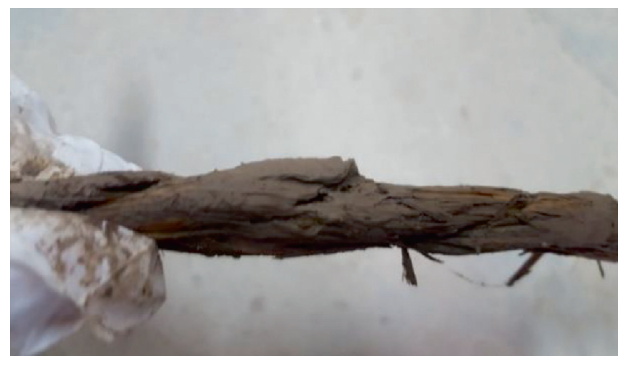

(a)

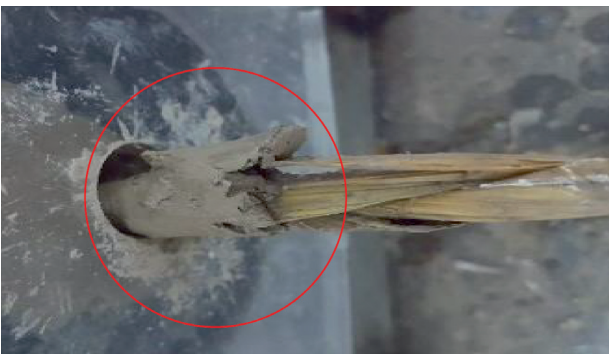

(b)

Figure 6: The appearance of sample before and after pull-out test. (a) Before test and (b) after test.

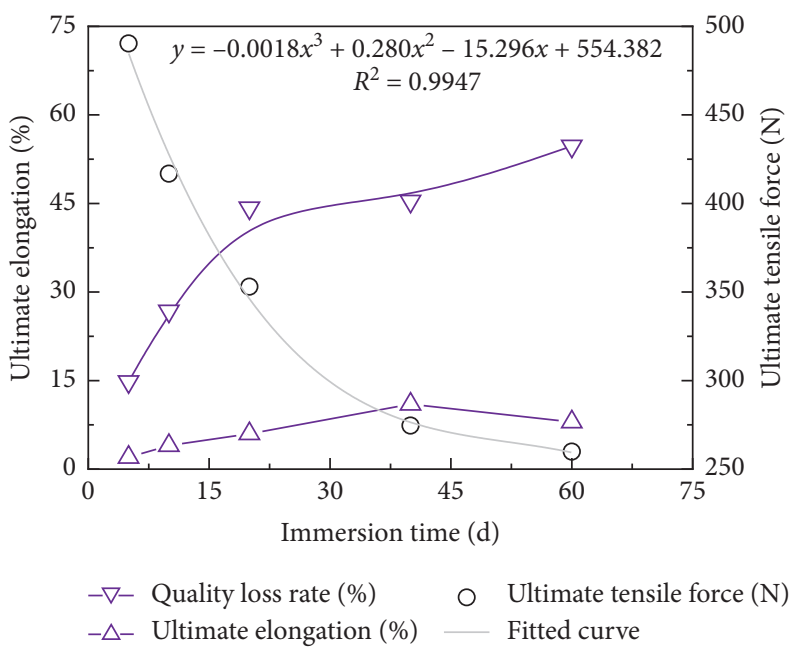

Figure 7: Ultimate tensile force, elongation, and mass loss rate with immersion time.

the second stage was relatively smooth and the degradation rate was slower. It is found that the degradation of rice straw occurred mainly within 20 days. This is because the degradation of different components in rice straw varies in degrading difficulty and speed. Protein and minerals in rice straw are easy to degrade, while lignin, hemicellulose, and cellulose take a long time to degrade. The degradable elements of rice straw rope were basically degraded after 20 days' immersion, while lignin and other elements were less degraded. The mass loss of rice straw rope was less during 20 to 40 days' immersion and began to degrade gradually after 40 days' immersion. The curve of the ultimate elongation of the sample with immersion time is also in Figure 7. It is noted that immersion time can change the ultimate elongation of the sample. With the increase of immersion time, the ultimate elongation of the sample increases first and then decreases. When immersion time is 40 days, the ultimate elongation of the sample is the highest of $11 \%$.

3.3. Tension Test Results. The variation of the peak value of tensile force with immersion time is shown in Figure 7. It is noted that the peak value of tensile force decreases with immersion time. When immersion time reaches 60 days, the peak value of tensile force decreases by $53 \%$ compared with the sample soaked for 5 days. This is because the sample degraded naturally in the immersion process, resulting in a certain degree of damage to lignin and cellulose in rice straw. Cellulose is an important component of the cell wall of straw, 

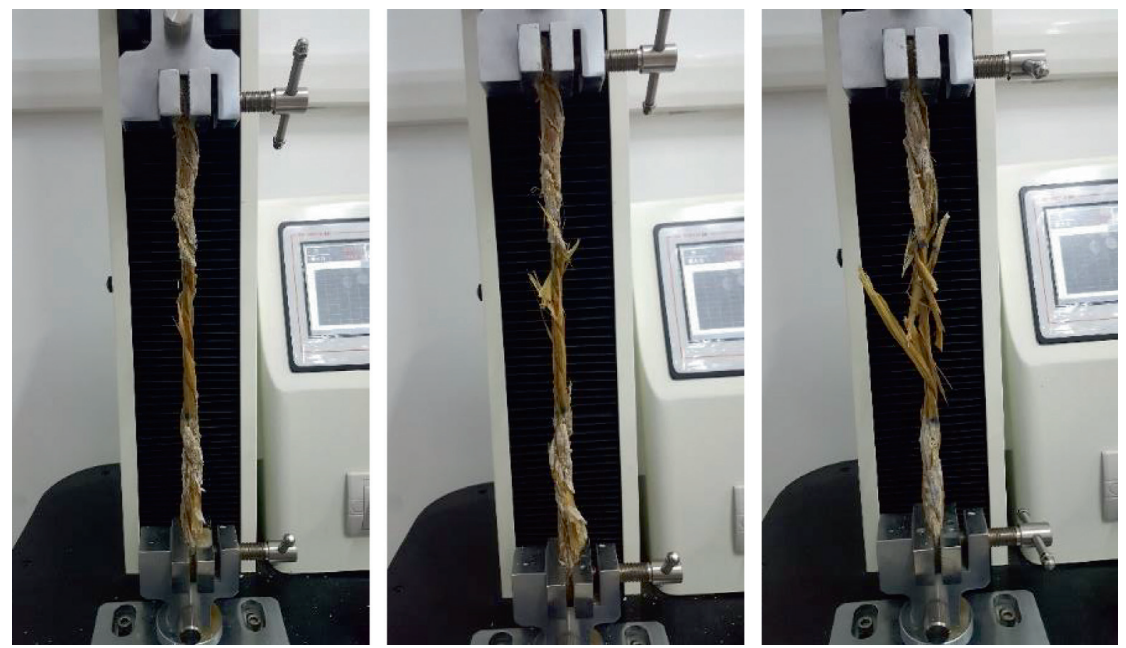

Figure 8: Tensile failure process.

which is responsible for providing tensile strength for straw. Lignin strengthens the cell wall of straw and further improves the tensile strength $[47,48]$. It should be pointed out that when immersion time is between 20 and 40 days, the mass loss rate of rice straw is only $1.13 \%$. The peak value of tensile force decreases by $78.45 \mathrm{~N}$, accounting for $34.04 \%$ of the total loss of the peak value of tensile force. It is indicated that the degradation of straw rope has not stopped during this period.

The failure process of the sample is shown in Figure 8. It is inferred that the sample begins to break from the more fragile straw fibers and then gradually break to the more tough straw fibers and finally to the remaining straw fibers. However, the residual straw fibers are generally weak in tensile properties. After the peak value appears, the sample will be completely destroyed soon. It is found that the stress of the straw rope is actually provided by two parts: main and secondary fibers. The main fiber is the main part and the secondary fiber is the auxiliary part. At the same time, the failure mode also changes the sample from brittle failure to ductile failure [49].

3.4. Interface Characteristics. The schematic interface between rice straw rope and dredger fill silt is shown in Figure 9. After the degradation of rice straw rope in water, the most intuitive change is the appearance and structure of rice straw rope. After immersion for a certain period of time, the rice straw is no longer tightly wound. It is hard to see the deterioration of the structure of the sample due to the tension of water $[50,51]$. The fibrosis of rice straw rope becomes obvious after immersion, while the connection between rice straw fibers and the cohesion losses gradually. The structure becomes loose, and the degree of looseness at both ends of the sample is higher than that at the middle part of the sample. When the immersion time of the sample reaches 60 days, the structure of the sample is completely lost. Complete cracking between fibers is appeared, and the appearance of the sample is no longer the straw rope. The straw of rice loses the connection and is arranged in parallel with each other.

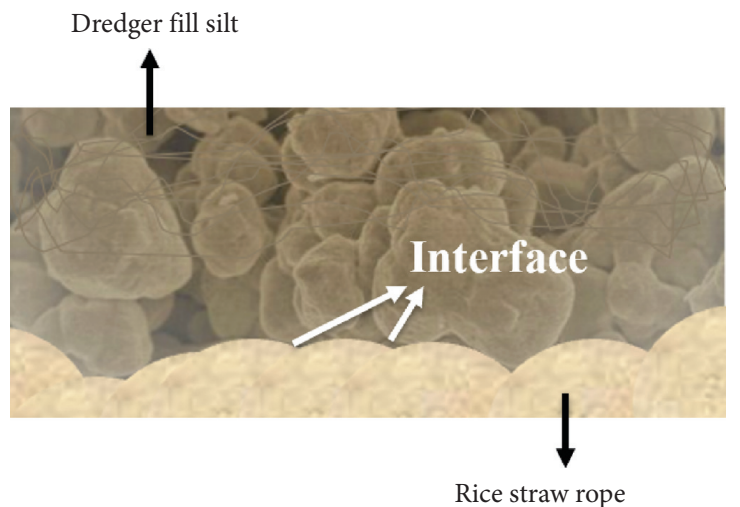

FIGURE 9: Interface schematic.

\section{Conclusions}

Based on the results, including pull-out test of rice straw rope with dredger fill silt, mass loss test, and tensile test of rice straw rope, the following conclusions may be drawn:

(1) When immersion time increased from 5 days to 60 days, the peak shear strength of the interface between straw rope and dredger silt decreased by $23.2 \%, 34.9 \%, 33.4 \%$, and $22.8 \%$ under normal stress of $20,40,60$, and $80 \mathrm{kPa}$, respectively. The peak value of interfacial shear strength rises with the increase of normal stress. The increase of normal stress can significantly improve the interface shear strength of rice straw rope and silt. When the normal stress is $40 \mathrm{kPa}$, the peak shear strength increases by up to $250.0 \%$. It is concluded that rice straw rope has reasonable interfacial shear strength for applications in treatment of dredger fill silt.

(2) The tensile force of straw rope increases slowly with the increase of tensile displacement. The failure mode of the samples after the first 20 days' immersion is brittle failure, and the failure mode changes to ductile failure after 40 days' immersion. 
The main stress mode of rice straw rope is the joint force of secondary straw fibers. The main straw fibers are gradually transferred from the weaker secondary straw fibers to the main straw fibers after failure. It is concluded that rice straw rope possesses proper tensile strength to be the reinforcement for dredger fill silt.

(3) The degradation of the sample in water experienced two stages: rapid degradation (immersion for 0 to 20 days) and slow degradation (immersion for 20 to 60 days). After 60 days' immersion, the average mass loss rate of the specimens was $54.7 \%$, and the degradation mainly occurred in the rapid degradation stage. The average mass loss rate was $44.3 \%$, accounting for $80.9 \%$ of the total. It is concluded that rice straw rope is suitable as the material for drainage and consolidation of dredger fill silt.

\section{Data Availability}

All the data presented and analyzed in the manuscript were obtained from laboratory tests at Soochow University in Suzhou China. All the laboratory testing data were presented in the figures and tables in the manuscript. The authors will be very pleased to share all the raw data. The data included in this manuscript are available upon request from the corresponding author.

\section{Conflicts of Interest}

The authors have no conflicts of interest.

\section{Acknowledgments}

This study was supported by the National Natural Science Foundation of China (51708377 and 51608059), Natural Science Foundation of Jiangsu Province (BK20170339), Natural Science Fund for Colleges and Universities in Jiangsu Province (17KJB560008), Open Fund of National Engineering Laboratory of Highway Maintenance Technology (Changsha University of Science \& Technology) (kfj180105), and project from Ministry of Housing, UrbanRural Development (2018-K7-011), Jiangsu Provincial Department of Water Resources (2018012).

\section{References}

[1] E. Karakan, N. Tanrinian, and A. Sezer, "Cyclic undrained behavior and post liquefaction settlement of a nonplastic silt," Soil Dynamics and Earthquake Engineering, vol. 120, pp. 214-227, 2019.

[2] A. Chegenizadeh, M. Keramatikerman, and H. Nikraz, "Liquefaction resistance of fibre reinforced low-plasticity silt," Soil Dynamics and Earthquake Engineering, vol. 104, pp. 372-377, 2018.

[3] J. H. Zhang, J. H. Peng, J. L. Zheng, and Y. S. Yao, "Characterisation of stress and moisture-dependent resilient behaviour for compacted clays in south China," Road Materials and Pavement Design, vol. 21, no. 1, pp. 262-275, 2020.

[4] J. Li, J. Zhang, G. Qian, J. Zheng, and Y. Zhang, "Three-dimensional simulation of aggregate and asphalt mixture using parameterized shape and size gradation," Journal of Materials in Civil Engineering, vol. 31, no. 3, Article ID 04019004, 2019.

[5] J. Zhang and Y. Yang, "Research and application on soft soil foundation treatment by static-dynamic drainage consolidation," in Proceedings of theSecond International Conference on IEEE Mechanic Automation and Control Engineering (MACE), pp. 3326-3329, Mongolia, China, July 2011.

[6] R. Y. Liang and S. L. Xu, High Vacuum Densification Method for Soft Soil Improvement, American Society of Civil Engineers, Reston, VA, USA, 2012.

[7] V. Vukadin, "The improvement of the loosely deposited sands and silts with the Rapid Impact Compaction technique on Brežice test sites," Engineering Geology, vol. 160, pp. 69-80, 2013.

[8] J. Zhang, J. Peng, W. Liu, and W. Lu, "Predicting resilient modulus of fine-grained subgrade soils considering relative compaction and matric suction," Road Materials and Pavement Design, pp. 1-13, 2019.

[9] K. M. Rollins and J. Kim, "Dynamic compaction of collapsible soils based on U.S. Case histories," Journal of Geotechnical and Geoenvironmental Engineering, vol. 136, no. 9, pp. 1178-1186, 2010.

[10] A. L. Preneron, J. E. Aubert, C. Magniont, C. Tribout, and A. Bertron, "Plant aggregates and fibers in earth construction materials: a review," Construction and Building Materials, vol. 111, pp. 719-734, 2016.

[11] A. Deng and S. L. Xu, "Consolidating dredge soil by combining vacuum and dynamic compaction effort," Ground Improvement and Geosynthetics, vol. 207, pp. 113-118, 2010.

[12] G. Xu, X. Yu, F. Wu, and Y. Yin, "Feasibility of vacuum consolidation in managing dredged slurries with wheat straw as drainage channels," KSCE Journal of Civil Engineering, vol. 21, no. 4, pp. 1154-1160, 2017.

[13] C. Liu, G. Z. Xu, and B. Xu, "Field study on the vacuum preloading of dredged slurry with wheat straw drainage," Geotechnical Engineering, vol. 22, pp. 4327-4333, 2008.

[14] A. B. Maslinda, M. S. Abdul Majid, M. J. M. Ridzuan, M. Afendi, and A. G. Gibson, "Effect of water absorption on the mechanical properties of hybrid interwoven cellulosiccellulosic fibre reinforced epoxy composites," Composite Structures, vol. 167, pp. 227-237, 2017.

[15] M. W. Bo, A. Arulrajah, and H. Nikraz, "Preloading and prefabricated vertical drains design for foreshore land reclamation projects: a case study," Proceedings of the Institution of Civil Engineers-Ground Improvement, vol. 11, no. 2, pp. 67-76, 2007.

[16] B. Indraratna, C. Rujikiatkamjorn, and I. Sathananthan, "Analytical and numerical solutions for a single vertical drain including the effects of vacuum preloading," Canadian Geotechnical Journal, vol. 42, no. 4, pp. 994-1014, 2005.

[17] K.-I. Sato, T. Nomura, and N. Yoshida, "Acceleration of selfweight consolidation for dredged clay using plastic board drain," in Proceedings of the International Offshore and Polar Engineering Conference, pp. 715-721, Kitakyushu, Japan, May 2001.

[18] K.-I. Sato and N. Yoshida, "Self-weight consolidation behavior of dredged clay improved by plastic board drain," in Proceedings of the International Offshore and Polar Engineering Conference, pp. 520-523, Seattle, WA, USA, May 2000.

[19] D. W. Kim, S. Y. Lee, K. S. Cho, M. H. Seo, and H. Kim, "Evaluation of discharge capacity of plastic board drain in simulated service situation," Polymer Testing, vol. 25, no. 8, pp. 986-993, 2006. 
[20] J. Zhang, J. Peng, L. Zeng, J. Li, and F. Li, "Rapid estimation of resilient modulus of subgrade soils using performance-related soil properties," International Journal of Pavement Engineering, pp. 1-8, 2019.

[21] L. Zeng, L.-Y. Xiao, J.-H. Zhang, and Q.-F. Gao, "Effect of the characteristics of surface cracks on the transient saturated zones in colluvial soil slopes during rainfall," Bulletin of Engineering Geology and the Environment, 2019.

[22] Q. Yua, R. H. Liu, K. Li, and R. J. Ma, "A review of crop straw pretreatment methods for biogas production by anaerobic digestion in China," Renewable and Sustainable Energy Reviews, vol. 107, pp. 51-58, 2019.

[23] P. Wambua, J. Ivens, and I. Verpoest, "Natural fibres: can they replace glass in fibre reinforced plastics?" Composites Science and Technology, vol. 63, no. 9, pp. 1259-1264, 2003.

[24] A. Diambra, E. Ibraim, D. Muir Wood, and A. R. Russell, "Fibre reinforced sands: experiments and modelling," Geotextiles and Geomembranes, vol. 28, no. 3, pp. 238-250, 2010.

[25] J. Zhang, F. Gu, and Y. Zhang, "Use of building-related construction and demolition wastes in highway embankment: laboratory and field evaluations," Journal of Cleaner Production, vol. 230, pp. 1051-1060, 2019.

[26] G. L. Sivakumar Babu and A. K. Vasudevan, "Strength and stiffness response of coir fiber-reinforced tropical soil," Journal of Materials in Civil Engineering, vol. 20, no. 9, pp. 571-577, 2008.

[27] J. Prabakar and R. S. Sridhar, "Effect of random inclusion of sisal fibre on strength behaviour of soil," Construction and Building Materials, vol. 16, no. 2, pp. 123-131, 2002.

[28] H. Güllü and A. Khudir, "Effect of freeze-thaw cycles on unconfined compressive strength of fine-grained soil treated with jute fiber, steel fiber and lime," Cold Regions Science and Technology, vol. 106-107, pp. 55-65, 2014.

[29] H. Wang, G. Wang, J. Qi et al., "Scarcity-weighted fossil fuel footprint of China at the provincial level," Applied Energy, vol. 258, Article ID 114081, 2020.

[30] M. Jacob, S. Joseph, and L. A. Pothan, "A study of advances in characterization of interfaces and fiber surfaces in lingocellulosic fiber-reinforced composites," Composite Interfaces, vol. 12, pp. 1-2, 2005.

[31] H. Wang, H. Schandl, G. Wang, L. Ma, and Y. Wang, "Regional material flow accounts for China: examining China's natural resource use at the provincial and national level," Journal of Industrial Ecology, vol. 23, no. 6, pp. 1425-1438, 2019.

[32] Q. Tang, P. Shi, Y. Zhang, W. Liu, and L. Chen, "Strength and deformation properties of fiber and cement reinforced heavy metal-contaminated synthetic soils," Advances in Materials Science and Engineering, vol. 2019, pp. 1-9, 2019.

[33] Q. Tang, P. X. Shi, Z. Yuan, S. J. Shi, X. J. Xu, and T. Katsumi, "Potential of zero-valent iron in remediation of $\mathrm{Cd}(\mathrm{II})$ contaminated soil: from laboratory experiment, mechanism study to field application," Soils and Foundations, .

[34] I. J. Beyerlein, Y. T. Zhu, and S. Mahesh, "On the influence of fiber shape in bone-shaped short-fiber composites," Composites Science and Technology, vol. 61, no. 10, pp. 1341-1357, 2001.

[35] Q. Tang, F. Gu, Y. Zhang, Y. Zhang, and J. Mo, "Impact of biological clogging on the barrier performance of landfill liners," Journal of Environmental Management, vol. 222, pp. 44-53, 2018.

[36] M. S. Khedkar and J. N. Mandal, "Pullout behaviour of cellular reinforcements," Geotextiles and Geomembranes, vol. 27, no. 4, pp. 262-271, 2009.
[37] Q. Tang, H. J. Kim, K. Endo, T. Katsumi, and T. Inui, "Size effect on lysimeter test evaluating the properties of construction and demolition waste leachate," Soils and Foundations, vol. 55, no. 4, pp. 720-736, 2015.

[38] Q. Tang, Y. Liu, F. Gu, and T. Zhou, "Solidification/stabilization of fly ash from a municipal solid waste incineration facility using Portland cement," Advances in Materials Science and Engineering, vol. 2016, Article ID 7101243, 10 pages, 2016.

[39] Q. Tang, Y. Zhang, Y. F. Gao, and F. Gu, "Use of cementchelated solidified MSWI fly ash for pavement material: mechanical and environmental evaluations," Canadian Geotechnical Journal, vol. 54, no. 11, pp. 1553-1566, 2017.

[40] Q. Tang, F. Gu, Y. F. Gao, T. Inui, and T. Katsumi, "Desorption characteristics of $\mathrm{Cr}(\mathrm{III}), \mathrm{Mn}(\mathrm{II})$ and $\mathrm{Ni}(\mathrm{II})$ in contaminated soil using citric acid and citric acid containing wastewater," Soils and Foundations, vol. 58, no. 1, pp. 50-64, 2018.

[41] M. R. Abdi and H. Mirzaeifar, "Effects of discrete short polypropylene fibers on behavior of artificially cemented Kaolinite," International Journal of Civil Engineering, vol. 14, no. 4, pp. 253-262, 2016.

[42] U. Chaduvula, B. V. S. Viswanadham, and J. Kodikara, “A study on desiccation cracking behavior of polyester fiberreinforced expansive clay," Applied Clay Science, vol. 142, pp. 163-172, 2017.

[43] Q. Tang, T. Katsumi, T. Inui, and Z. Li, "Influence of $\mathrm{pH}$ on the membrane behavior of bentonite amended Fukakusa clay," Separation and Purification Technology, vol. 141, pp. 132-142, 2015.

[44] Q. Tang, F. Gu, H. Chen, C. Lu, and Y. Zhang, "Mechanical evaluation of bottom ash from municipal solid waste incineration used in roadbase," Advances in Civil Engineering, vol. 2018, Article ID 5694908, 8 pages, 2018.

[45] Q. Tang, T. Katsumi, T. Inui, and Z. Li, "Membrane behavior of bentonite-amended compacted clay," Soils and Foundations, vol. 54, no. 3, pp. 329-344, 2014.

[46] Y. Zhou, L. Pan, Q. Tang, Y. Zhang, N. Yang, and C. Lu, "Evaluation of carbonation effects on cement-solidified contaminated soil used in road subgrade," Advances in Materials Science and Engineering, vol. 2018, Article ID 5271324, 15 pages, 2018.

[47] C. S. Tang, D. Y. Wang, Y. J. Cui, B. Shi, and J. Li, “Tensile strength of fiber-reinforced soil," Journal of Materials in Civil Engineering, vol. 28, Article ID 04016031, 2016.

[48] J. Li, C. Tang, D. Wang, X. Pei, and B. Shi, "Effect of discrete fibre reinforcement on soil tensile strength," Journal of Rock Mechanics and Geotechnical Engineering, vol. 6, no. 2, pp. 133-137, 2014.

[49] M. Tajdin, M. H. Bonab, and S. Golmohamadi, "An experimental investigation on effect of adding natural and synthetic fibers on mechanical and behavioral parameters of soil-cement materials," International Journal of Civil Engineering, vol. 16, no. 4, pp. 353-370, 2018.

[50] Q. Tang, X. Tang, M. Hu, Z. Li, Y. Chen, and P. Lou, "Removal of $\mathrm{Cd}(\mathrm{II})$ from aqueous solution with activated Firmiana Simplex Leaf: behaviors and affecting factors," Journal of Hazardous Materials, vol. 179, no. 1-3, pp. 95-103, 2010.

[51] Q. Tang, X. Tang, Z. Li et al., "Zn(II) removal with activated Firmiana simplex leaf: kinetics and equilibrium studies," Journal of Environmental Engineering, vol. 138, no. 2, pp. 190-199, 2012. 